\title{
AVALIAÇÃO DA PERDA DE SOLO POR EROSÃO HÍDRICA NO CONCELHO DE TAROUCA (PORTUGAL) E SUA INFLUÊNCIA NA MORFOGÉNESE ATUAL
}

\author{
ASSESSMENT OF SOIL LOSS BY WATER IN THE TAROUCA COUNTY \\ (PORTUGAL) AND ITS INFLUENCE IN ACTUAL MORPHOGENESIS
}

\author{
Bruno Miguel Meneses \\ Instituto de Geografia e Ordenamento do Território, Universidade de Lisboa \\ Avenida Prof. Gama Pinto, Lisboa. Caixa Postal: 1649-003, Portugal \\ E-mail: bmeneses@campus.ul.pt
}

\section{Informações sobre o Artigo}

Data de Recebimento:

22/02/2014

Data de Aprovação:

02/08/2014

\section{Palavras-chave:}

Erosão hídrica, USLE,

Morfogénese atual.

\section{Keywords:}

Erosion by Water, USLE, Actual Morphogenesis

\section{Resumo:}

A determinação de áreas suscetíveis à erosão hídrica é fundamental na tomada de decisões que envolvam atividades relacionadas com o uso do solo, nomeadamente atividades agrícolas. Sendo o Concelho de Tarouca (área de estudo) uma área com elevada dependência agrícola é fundamental a preservação do solo, evidenciandose aqui o reconhecimento das áreas mais suscetíveis à erosão hídrica. Neste sentido, estimou-se a perda de solo nesta área pela Equação Universal de Perda de Solo (EUPS) e avaliou-se o impacto destas perdas na morfogénese atual. Os resultados aqui obtidos permitiram aferir as áreas mais suscetíveis à erosão hídrica, destacando-se a influência de vários fatores, como o relevo, precipitação, o seu coberto e práticas desenvolvidas, na variação da distribuição da erosão hídrica.

\begin{abstract}
:
The determination of areas susceptible to erosion by water is fundamental to the process of decision making involving activities related to land use, in particular agricultural activities. Being the Tarouca County (study area) an area with high dependence on agriculture, the preservation of the soil becomes essential, in particular in areas more susceptible to erosion. Therefore, the soil loss in this area was estimated using the Universal Soil Loss Equation (USLE) and the impact of these losses on currently morphogenesis was also assessed. The results obtained allowed to assess the areas most susceptible to erosion, with some factors assuming a significant relevance, factors such as relief, precipitation, land cover and the practices developed, on the variation of distribution of water erosion.
\end{abstract}


1. O Solo, a Erosão Hídrica e Seus Impactes na Morfogénese Atual

Os solos são considerados um dos principais recursos ou sistemas de suporte da vida e do bem-estar humano, pois fornecem o substrato para as raízes, retêm água o tempo suficiente para esta ser utilizada pelas plantas e fixam nutrientes essenciais para a vida (Brilha e Sá, 2007). A sua degradação, considerada por Wasson (1987) como a perda de utilidade para os seres vivos devido à sua modificação, assume-se como um verdadeiro problema da atualidade, com grandes perturbações económicas e sociais, que se traduzem no condicionamento do desenvolvimento dos países (Lal, 1998).

Pela constante modificação da cobertura dos solos e, também, pelas ações antrópicas neles desenvolvidas tem-se assistido à sua degradação, muitos deles essenciais para a prática da agricultura (Meneses, 2013a). Nos solos ocupados por floresta também se têm verificado elevadas perdas quando estes são fustigados por incêndios, do qual resulta a perda da sua cobertura vegetal deixando-os totalmente desprotegidos à precipitação, potenciando assim a ocorrência de movimentos de massa (erosão hídrica, deslizamentos, escoadas, entre outros processos). Após a perceção das consequências resultantes destes problemas tem-se atuado na tentativa de minimizar consequências destas atividades e eventos, optando-se por medidas sustentáveis e de mitigação. É neste contexto que a determinação das áreas mais suscetíveis à erosão hídrica se torna fundamental, permitindo a atuação imediata sobre as áreas mais afetadas (medida reativa) e na implementação de políticas que visam a sua sustentabilidade, entendendo-se por medidas preventivas (Meneses, 2011a).

Existem vários modelos para a determinação da erosão hídrica, como por exemplo o CREAMS (Knisel, 1980), ANSWERS (Beasley et al., 1980), WEPP (Lane et al., 1992), EUROSEM (Morgan, 1994), LISEM (Roo et al., 1996), entre outros. Um dos mais utilizados é a Equação Universal de Perda de Solo ou USLE (Universal Soil Loss Equation) proposta por Wischmeier e Smith $(1965$; 1978), versão posteriormente revista (RUSLE) por Renard et al. (1997). Atualmente, com a evolução da tecnologia, é possível integrar diversa informação neste modelo (e.g. ocupação do solo determinada a partir de imagens de satélite), o que o torna ainda mais procurado para a previsão da perda do solo e na determinação de áreas suscetíveis à erosão hídrica.

Muitas vertentes perdem a sua sustentação quando a sua base é erodida, desencadeando-se grandes movimentos de vertente, o que tem implicações na morfogénese de determinados territórios (Meneses, 2011b). Por outro lado, a constante erosão do solo nas suas mais variadas aceções também contribui para a modelação das vertentes, com impactes a jusante, como por exemplo a acumulação do material erodido a montante, destruição de bens materiais ou culturas (consequências económicas), entre outros.

\section{Metodologia}

\section{1 Área de estudo - aspetos físicos e climáticos}

A área de incidência deste estudo (Figura 1) é o Concelho de Tarouca $\left(100,1 \mathrm{~km}^{2}\right)$. Nesta predominam as atividades agrícolas, fator que traduz a elevada importância da preservação dos solos (Meneses, 2013a).

Para o desenvolvimento das atividades agrícolas muitas das vertentes foram alteradas antropicamente (através da construção de socalcos), de forma a obter-se maior aproveitamento deste recurso natural (solo), representando as áreas agrícolas cerca de $20,68 \%$ da área total em estudo. Neste tipo de ocupação destacam-se os pomares, áreas com ocupação mista de espécies florestais e culturas anuais $(17,73 \%)$.

Porém, sobressaem as florestas na ocupação deste território pela extensa área ocupada $(59,04 \%)$, predominando aqui o pinheiro bravo (Pinus pinaster) e os carvalhos (Quercus pyrenaica).

Com menor expressão, apresentam-se as áreas urbanas e de inculto $(2,56 \%)$.

Esta área insere-se numa região com clima continental acentuado pela posição topográfica (Daveau et al., 1985), onde a orografia é responsável pela distribuição irregular da precipitação (efeito de abrigo dos vales mais profundos).

Quanto à precipitação, como se pode observar no gráfico da Figura 2 (elaborado a partir de dados das estações meteorológicas localizadas em torno e na área de estudo - Castro D'Aire, Mezio e Tarouca) destacam-se os meses de Novembro, Dezembro e Janeiro com os valores médios mais elevados. Junho e Julho são os meses que apresentam menor precipitação (período seco). 


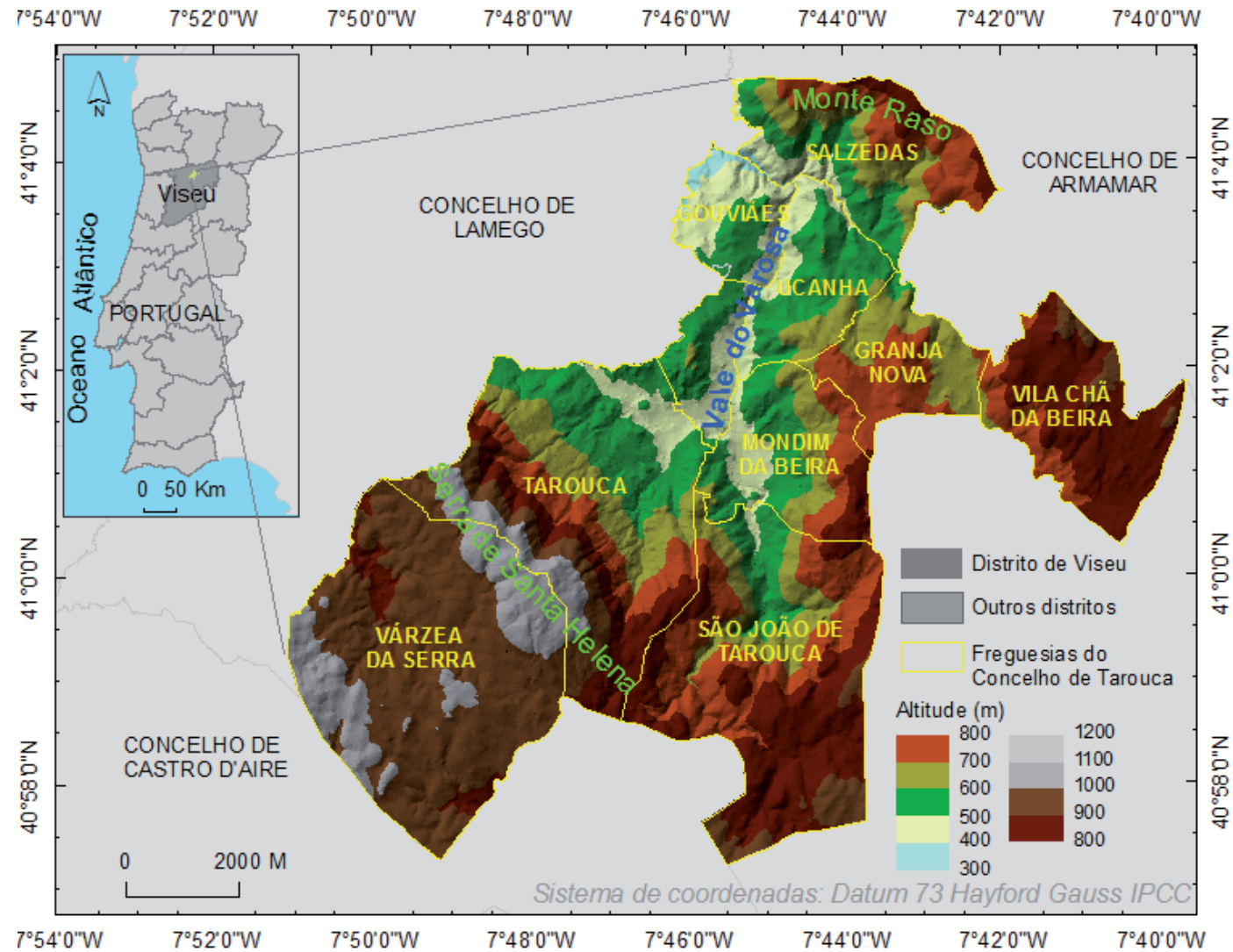

Figura 1 - Área de Estudo (Concelho de Tarouca).

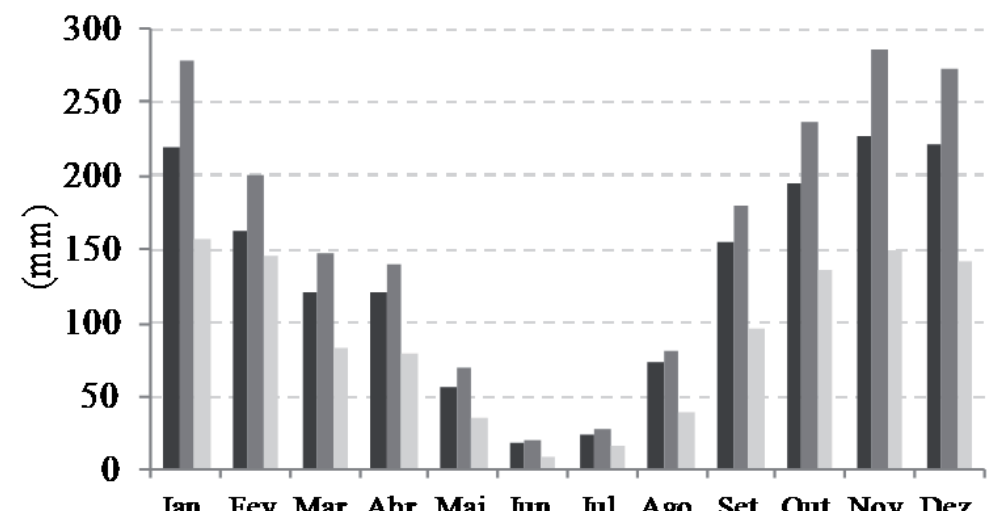

Jan. Fev. Mar. Abr. Mai. Jun. Jul. Ago. Set. Out. Nov. Dez.

-Castro D'Aire $\quad$ Mezio(Paiva) $\quad$ Tarouca

Figura 2 - Precipitação média mensal registada nas estações meteorológicas de Castro D’Aire, Mezio (Paiva) e Tarouca entre 1944-95.

Esta área também é caraterizada pelas precipitações intensas, sobretudo em Novembro, período em que os solos estão mais desprotegidos devido a vários fatores como por exemplo a colheita de culturas, extensas áreas de espécies arbustivas e arbóreas de folha caduca, elevada ocorrência de incêndios florestais, dos quais resultam grandes extensões de área ardida.
Os sulcos e ravinas presentes nas vertentes da Serra de Santa Helena e no Monte Raso (Figura 3) revelam a perda de grandes quantidades de solo destes locais. Estes por vezes potenciam outros processos, como é o caso de desabamentos de blocos rochosos, escoadas, entre outros tipos de movimentos de vertente (Meneses, 2011b). Além destes processos, devido às temperaturas 
negativas durante as noites mais frias de inverno ocorrem outros processos que originam a mobilização dos solos como é o caso a formação de Pipkrakes (Meneses, 2013b). Esta perda de solos pelos vários processos vai contribuindo para a modelação das vertentes da área de estudo, interferindo assim na morfogénese atual.

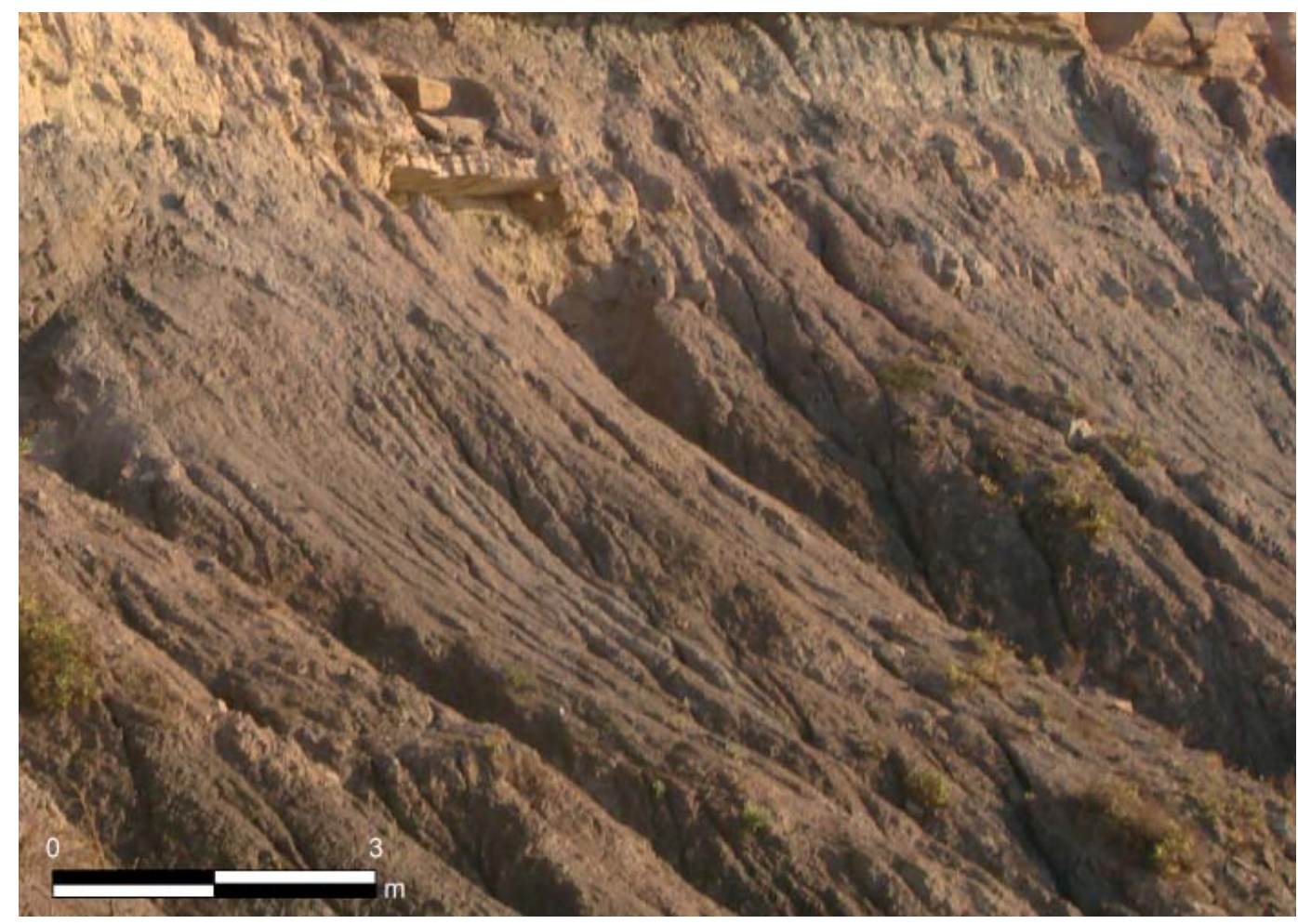

Figura 3 - Sulcos e ravinas resultantes da erosão hídrica numa vertente do Monte Raso (N da área de estudo).

\subsection{Determinação da erosão hídrica}

Neste estudo optou-se pela metodologia USLE para a avaliação da perda de solo por erosão hídrica (Wischmeier e Smith, 1965, 1978; Petan et al., 2010). Segundo os autores anteriormente referidos, esta equação é composta por seis fatores:

\section{$\mathrm{A}=\mathrm{RKLSCP}$}

onde, A é a estimativa da erosão (ton.ha ${ }^{-1} \cdot$ ano $^{-1}$ ); R o fator de erosividade da chuva/escorrência; $\mathrm{K}$ o fator de erodibilidade do solo; $\mathrm{L}$ o fator de comprimento da vertente; $\mathrm{S}$ o fator de inclinação da vertente; $\mathrm{C}$ o fator de cobertura do solo e $\mathrm{P}$ o fator prática agrícola.

Este modelo multiplicativo tem por base o tratamento parcelar de cada um dos fatores que integram este processo, resultando a estimativa da erosão específica, ou seja, a perda de solo por unidade de área e por unidade de tempo.
O fator erosividade (R) determina-se em função da intensidade da precipitação e traduz a capacidade ou poder de destacar e arrastar as partículas de solo pela chuva. Segundo Wischmeier e Smith (1978), este é definido pelo índice de erosividade $\left(\mathrm{EI}_{30}\right)$, ou seja, o produto da energia cinética da precipitação (Equações 2 e 3, conforme referido em Foster et al.,1981) pela máxima intensidade da mesma num período de 30 minutos.

$$
\begin{gathered}
e=0,119+0,0873 * \log _{10}(\mathrm{I}) \quad\left(\mathrm{se} \mathrm{I} \leq 76 \mathrm{~mm} \cdot \mathrm{h}^{-1}\right) \\
e=0,26 \quad\left(\text { se I }>76 \mathrm{~mm} \cdot \mathrm{h}^{-1}\right)
\end{gathered}
$$

onde $e$ corresponde à energia cinética da precipitação $\left(\mathrm{Mj} \mathrm{ha}^{-1} \cdot \mathrm{mm}^{-1}\right)$ e I à intensidade da precipitação $\left(\mathrm{mm} \cdot \mathrm{h}^{-1}\right)$.

Devido à falta de dados de precipitação, nem sempre é possível obter detalhadamente a sua variação para a aplicação das equações apresentadas anteriormente, inviabilizando a sua utilização. Porém, Bertoni e Lombardi Neto (1990) apresentam uma metodologia mais simplificada no cálculo do fator R (Equações 4 e 5). 


$$
\mathrm{EI}=89,5 *\left(\frac{r^{2}}{\mathrm{P}}\right)^{0,85}
$$

$$
\mathrm{R}=\mathrm{EI} * 12 \mathrm{meses}
$$

correspondendo, EI à média mensal do índice de erosão $\left(\mathrm{Mj} \mathrm{ha}^{-1} \cdot \mathrm{mm}\right) ; \mathrm{r}^{2}$ à precipitação média mensal $(\mathrm{mm}) ; \mathrm{P}$ à precipitação média anual $\left(\mathrm{mm}^{\mathrm{ano}} \mathrm{N}^{-1}\right)$ e R à erosividade da chuva $\left(\mathrm{Mj}_{\mathrm{j}} \mathrm{ha}^{-1} \cdot \mathrm{mm} \cdot \mathrm{ano} \mathrm{o}^{-1}\right)$.

Neste estudo o fator $\mathrm{R}$ foi calculado com recurso aos Sistemas de Informação Geográfica (SIG), onde se obteve um Modelo Numérico de Erosividade, elaborado a partir da equação da regressão linear obtida entre o EI calculado a partir da precipitação média anual registada nas três estações meteorológicas anteriormente referidas e a sua altitude.
O fator erodibilidade (K) determina-se por comparação com a perda de solo numa parcela de terreno $(22,13 \mathrm{~m}$ de comprimento e $9 \%$ de declive) permanentemente a descoberto através da mobilização de solo no sentido de maior declive, avaliando-se a resistência do solo à ação da chuva e da escorrência superficial $(\mathrm{Mj}$. $\left.\mathrm{ha}^{-1}\right)$. Este varia consoante as propriedades físicas do solo, nomeadamente a estrutura do solo, granulometria, teor em matéria orgânica e permeabilidade.

Para este estudo recolheram-se amostras nos vários tipos de solo que compõem a área em análise, posteriormente analisadas em laboratório onde se determinou a sua granulometria, teor de matéria orgânica e permeabilidade. Para a determinação da permeabilidade recorreu-se ao esquema representado na Figura 4.

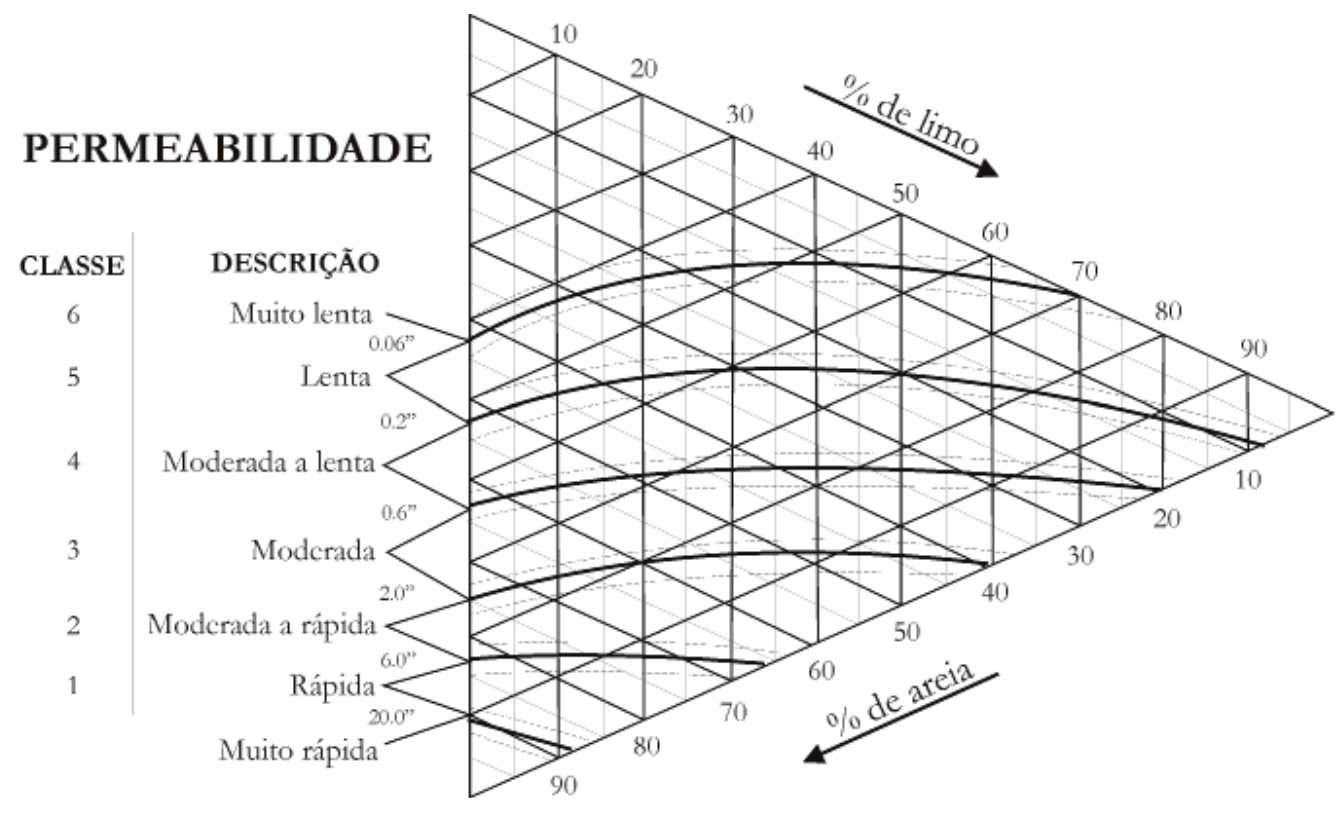

Figura 4 - Classes de permeabilidade em relação à textura do solo (adaptado de PIMENTA, 1998).

O fator K pode determina-se através da Equação 6 , quando o solo tiver uma percentagem de areia fina e limo inferior a $70 \%$.

$\mathrm{K}=\frac{2,1 * \mathrm{M}^{1,14} * 10^{-4} *(12-\mathrm{MO})+3,25 *(\delta-2)+2,5 *(\beta-3)}{759,3}$

onde, $\mathrm{K}$ é a erodibilidade (ton.h. $\mathrm{MJ}^{-1} \cdot \mathrm{mm}^{-1}$ ), $\mathrm{M}$ é o resultado da $\%$ de limo e areia muito fina $*(100-\%$ de argila); MO a \% de matéria orgânica; $\delta$ o código da classe de estrutura do solo (1 a 4) e $\beta$ o código da classe de permeabilidade do solo (1 a 6 ). A percentagem de argila é igual a $100-$ limo + areia muito fina - areia grossa.

O fator topográfico (LS) obtém-se a partir da relação entre o comprimento da vertente (L), definido por comparação com a perda de solo numa parcela com $22,13 \mathrm{~m}$ e o seu declive (S). Para a determinação deste fator em ambiente SIG na área de estudo, optou-se pela metodologia apresentada por Engel (1999) e Simms et al. (2003). Nesta considera-se os fluxos acumulados obtidos a partir da direção de fluxos para a determinação de segmentos ao longo da vertente e, também, o tamanho da célula (Equação 7). 


$$
\mathrm{LS}=\left(\frac{\mathrm{FA} * \mathrm{TC}}{22,13}\right)^{0,4} *\left(\frac{\operatorname{sinS}}{0,0896}\right)^{1,3}
$$

Correspondendo o LS ao fator topográfico, FA aos fluxos acumulados, TC ao tamanho da célula e $\mathrm{S}$ ao declive (graus).

Quanto ao fator coberto do solo (C), este traduz a perda de solo em áreas com determinada cobertura vegetal, sendo este a razão entre o quociente de perda de solo de uma parcela com determinada cultura e maneio, e uma parcela mantida permanentemente a descoberto por práticas de mobilização de solo, sob condições idênticas (Wischmeier e Smith, 1978; Tomás, 1993). Este fator varia consoante a percentagem de área ocupada, devendo diminuir ou aumentar se esta cobertura é maior ou menor, respetivamente. Este fator pode determinar-se a partir da informação de uso e ocupação do solo, neste caso Carta de Ocupação do Solo (COS) e CORINE Land Cover (CLC), ou outra cartografia com esta temática, de forma a possibilitar a atribuição dos valores representados no Quadro 1.

Quadro 1: Fator coberto do solo (adaptado de PIMENTA, 1998 e TOMÁs, 1993).

\begin{tabular}{lc}
\hline Tipo de cobertura e uso do solo & Fator C \\
\hline Agricultura com espaços naturais e seminaturais & 0,30 \\
Culturas temporárias de regadio & 0,20 \\
Culturas temporárias de sequeiro & 0,30 \\
Culturas temporárias e/ou pastagens associadas a & 0,05 \\
culturas permanentes & 0,10 \\
Florestas abertas - cortes e novas plantações & 0,05 \\
Florestas de resinosas & 0,05 \\
Florestas mistas & 0,02 \\
Matos & 0,02 \\
Pastagens permanentes & 0,05 \\
Pomares & 0,20 \\
Sistemas culturais e parcelares complexos & 0,01 \\
Tecido urbano descontínuo & 0,05 \\
Vegetação esparsa & 0,02 \\
Vegetação herbácea natural & 0.20 \\
Vinhas &
\end{tabular}

Para minimizar a desatualização da informação geográfica da ocupação do solo anteriormente referida na área de estudo, complementou-se a determinação do fator $\mathrm{C}$ com os índices de cobertura vegetal (NDVI - Normalized Difference Vegetation Index) obtidos pela combinação de bandas espectrais das imagens de satélite Landsat $5^{\mathrm{TM}}$ (recurso à Deteção Remota). Nesta abordagem interessou, particularmente, determinar as áreas com maior variação de biomassa entre o período mínimo e máximo vegetativo, por se tratar de áreas mais suscetíveis à erosão hídrica em função da variação do fator de proteção proporcionado por este tipo cobertura. Esta variação obteve-se a partir da seguinte equação (Meneses, 2011a):

$$
\mathrm{I}_{\mathrm{VB}}=\frac{\operatorname{Exp}(-1 *(\mathrm{NDVI} \chi-\mathrm{NDVI} \gamma)}{10}
$$

correspondendo, $\mathrm{I}_{\mathrm{VB}}$ ao índice de variação de biomassa entre o máximo vegetativo e mínimo vegetativo; NDVI $\chi$ ao índice de vegetação por diferença normalizada do máximo vegetativo e NDVI $\gamma$ ao índice de vegetação por diferença normalizada do mínimo vegetativo.

Com os valores apresentados no Quadro 1, representados em formato raster (resolução de $10 \mathrm{~m}$ ) na área de estudo, e com o $\mathrm{I}_{\mathrm{VB}}$ no mesmo formato, obteve-se o fator $\mathrm{C}$, sendo este o resultado da média entre os valores dos dois mapas temáticos anteriormente referidos.

O fator prática agrícola $(\mathbf{P})$ representa a influência das práticas agrícolas na erosão hídrica de solos cultivados expostos à precipitação, ou seja, a variação de sedimentos removidos em função da escorrência superficial derivada destas práticas (Wischmeier e Smith, 1978; Simms et al., 2003). Os valores considerados na determinação da erosão específica apresentam-se no Quadro 2, sendo estes atribuídos ao mapa temático criado para o efeito através da vectorização de práticas agrícolas observadas sobre ortofotomapas, com auxílio da topografia.

Quadro 2: Valores do fator P (adaptado de Wischmeier e Smith, 1978 e Tomás, 1993).

\begin{tabular}{cccc}
\hline \multirow{2}{*}{$\begin{array}{c}\text { Declive da } \\
\text { superfície } \\
(\%)\end{array}$} & $\begin{array}{c}\text { Cultura ao } \\
\text { longo das } \\
\text { curvas de nível }\end{array}$ & $\begin{array}{c}\text { Cultura em } \\
\text { faixas }\end{array}$ & $\begin{array}{c}\text { Cultura em } \\
\text { terraços }\end{array}$ \\
\hline $0-1$ & 0,00 & 0,00 & 0,00 \\
$2-7$ & 0,50 & 0,25 & 0,10 \\
$8-12$ & 0,60 & 0,30 & 0,12 \\
$13-18$ & 0,80 & 0,40 & 0,16 \\
$19-24$ & 0,90 & 0,45 & 0,18 \\
$\geq 25$ & 1,00 & 0,50 & 0,21 \\
\hline
\end{tabular}

A USLE, por ser um modelo multiplicativo, neste ensaio considerou-se que no fator $\mathrm{P}$ as áreas florestais 
deveriam corresponder à milésima parte da unidade, ao admitir a influência de atividades antrópicas (desflorestação, pisoteio, entre outros) e de animais (pastoreio) na perda de solo ao alterar-se a proteção do solo proporcionada por este tipo de cobertura. Assim, nas áreas com este tipo de ocupação é possível obter um resultado diferente de 0 quando multiplicado pelos restantes fatores.

\section{Resultados e Discussão}

A erosividade na área de estudo é superior nas área de maior altitude (Figura 5). Este resultado deve-se à ocorrência de maior precipitação neste território, por um lado devido ao "desabrigo" ou falta de obstáculos na área xistenta às massas de ar húmidas (marítimas) provenientes de oeste, e por outro devido ao efeito em $\mathrm{V}$ proporcionado pelas barreiras montanhosas de Montemuro e Marão-Alvão (Daveau et al., 1985; Pedrosa et al., 2004) na canalização destas massas de ar húmido, proporcionando chuvas orográficas, daí se destacar a Serra de Santa Helena com os valores mais elevados de R (1314 Mj.ha-1 $\left.{ }^{-1} \mathrm{~mm} \cdot \mathrm{ano}^{-1}\right)$. Já o fundo dos vales é onde se observa os valores mais reduzidos, devendo-se ao efeito de abrigo proporcionado pela orografia à precipitação, o que se traduz por menor capacidade ou

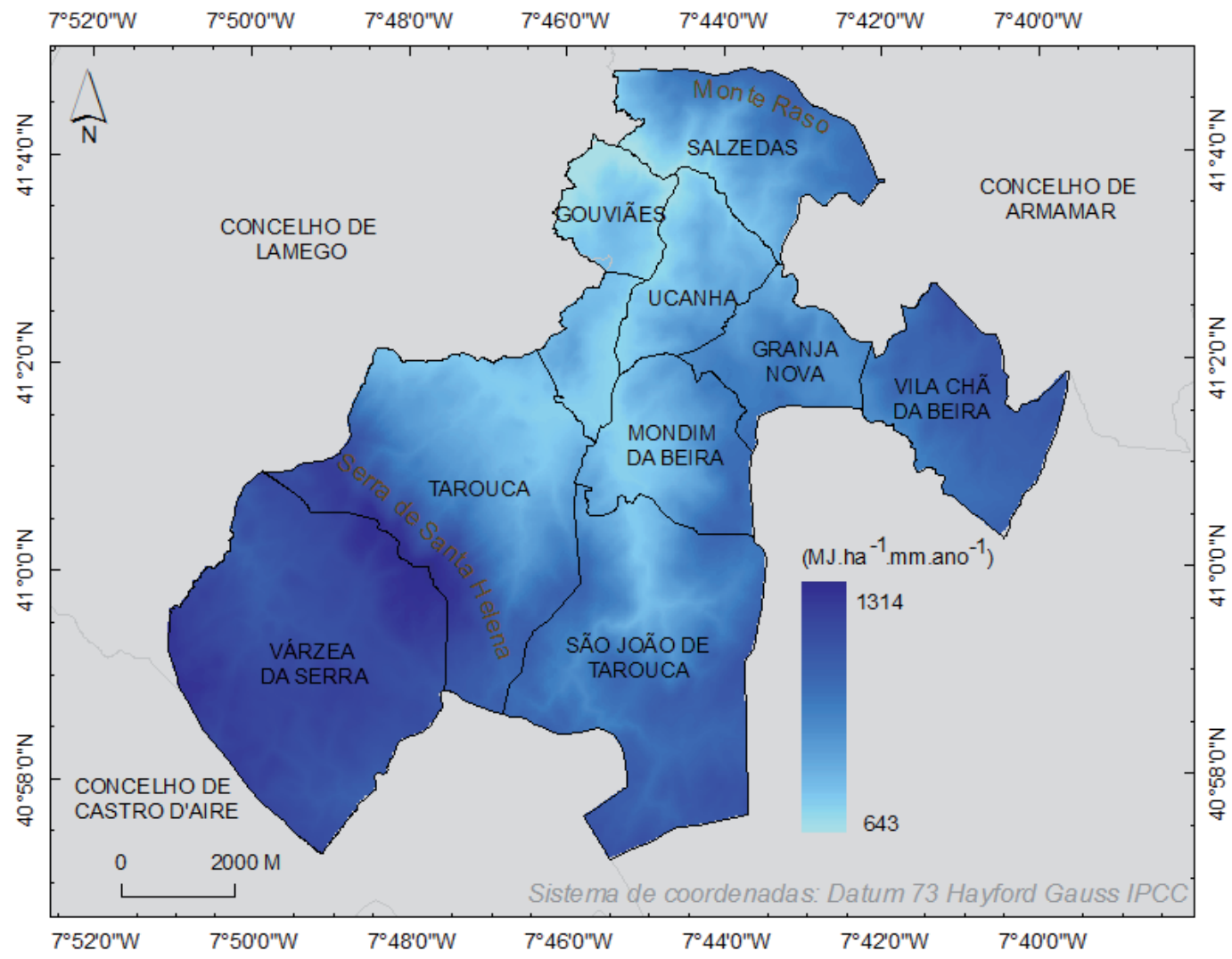

Figura 5 - Representação espacial da erosividade (Fator R).

poder de destacamento e arrastamento das partículas de solo pela chuva incidente sobre estas áreas.

A erodibilidade também é superior nesta Serra e deve-se à constituição dos solos da mesma, neste caso Leptosolos úmbricos de granitos e rochas afins. Nas análises de laboratório obteve-se para este tipo de solo a seguinte granulometria (\%): 40,29 de cascaclho e outros, 44,89 de areia grossa, 0,37 areia fina, 0,13 de limo (silte), 11,57 de argila e 2,75 de matéria orgânica. A estrutura obtida para este solo foi de 3 , com permeabilidade de classe 6 .

Nos Cambissolos dístricos órticos em áreas de granitos e rochas afins (ocupam essencialmente a freguesia de Granja Nova) e nos Cambissolos úmbricos 


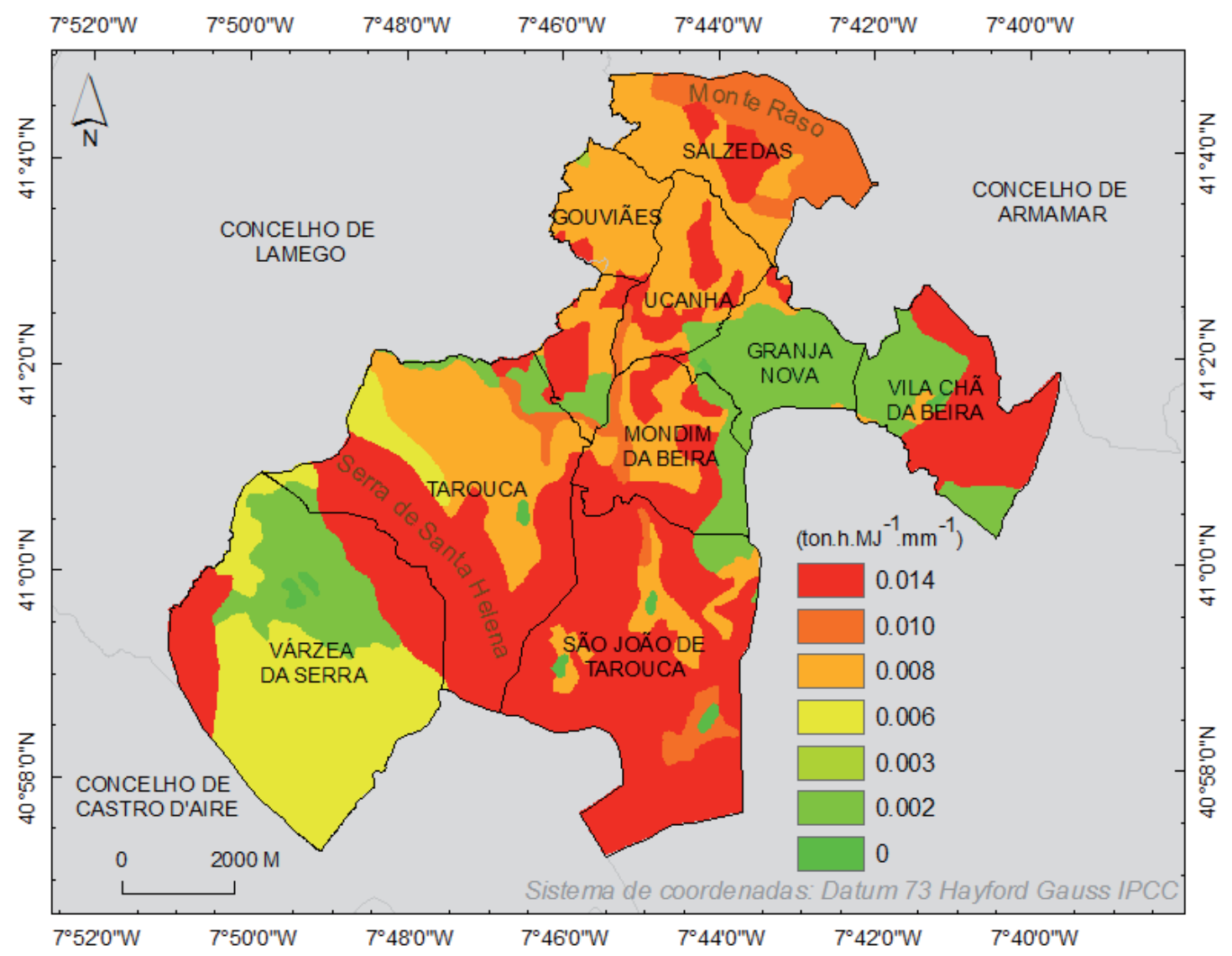

Figura 6 - Representação espacial da erodibilidade (Fator K).

órticos em áreas de xistos e rochas afins (freguesia de Várzea da Serra) verificou-se valores reduzidos de erodibilidade (Figura 6), devendo-se à sua constituição física (elevada percentagem de areia grossa, argila e materia orgânica; estrutura 1 e permeabilidade 5).

No fator topográfico destacam-se as vertentes da Serra de Santa Helena com os valores mais elevados, devendo-se neste caso à extensão das mesmas e ao seu declive (Figura 7). Com as mesmas caraterísticas apresentam-se algumas vertentes do Monte Raso e também do Vale do Varosa onde este é mais entalhado. $\mathrm{Na}$ Freguesia de Várzea da Serra observam-se maioritariamente valores reduzidos devido à morfologia desta área (cabeços xistentos de forma arredondada e com fraco declive).

Analisando o mapa do fator cobertura de solo (Figura 8), observam-se os valores mais elevados nos locais onde há maior exposição dos solos à precipitação, correspondendo neste caso aos solos ocupados por culturas temporárias de sequeiro e vinhas. Destaque também para as áreas onde ocorreram incêndios florestais pelos valores elevados (e.g. freguesia de São João de Tarouca e Serra de Santa Helena), demonstrando-se a informação obtida pelo índice de variação de biomassa eficiente na identificação de áreas onde a perda de solo por erosão hídrica pode aumentar devido à ausência de proteção. As áreas com os valores mais reduzidos estão ocupadas por floresta de resinosas e matos.

O fator prática agrícola também se destaca nos solos ocupados por culturas de sequeiro (realizadas em faixas) e nas vinhas (plantadas ao longo das curvas de nível), devendo-se sobretudo ao declive das áreas onde se localizam estas culturas (Figura 9). Os solos florestais apresentam valores reduzidos, contudo nestes verificou-se (in loco) que há influência antrópica (atividades desportivas, motorizadas, recolha de lenha, entre outras) e dos animais que aqui pastoreiam (pisoteio do solo), fatores que contribuem para a desagregação do solo e respetiva perda por erosão hídrica, atribuindo-se assim o valor de 0,01 às áreas onde se observou estas situações. 
Avaliação da Perda de Solo por Erosão Hídrica no Concelho de Tarouca (Portugal) e sua Influência na Morfogénese

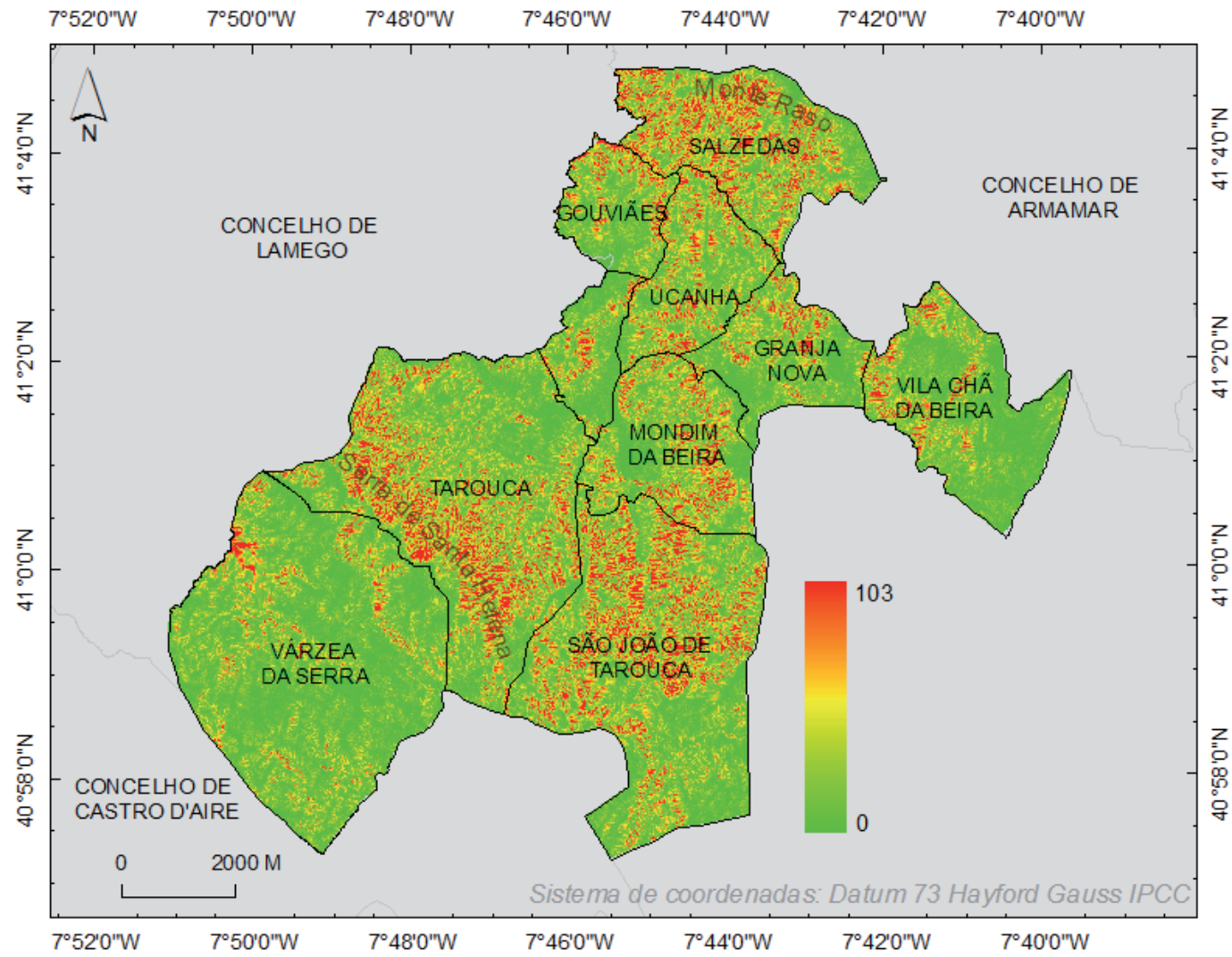

Figura 7 - Representação espacial do Fator Topográfico (LS).

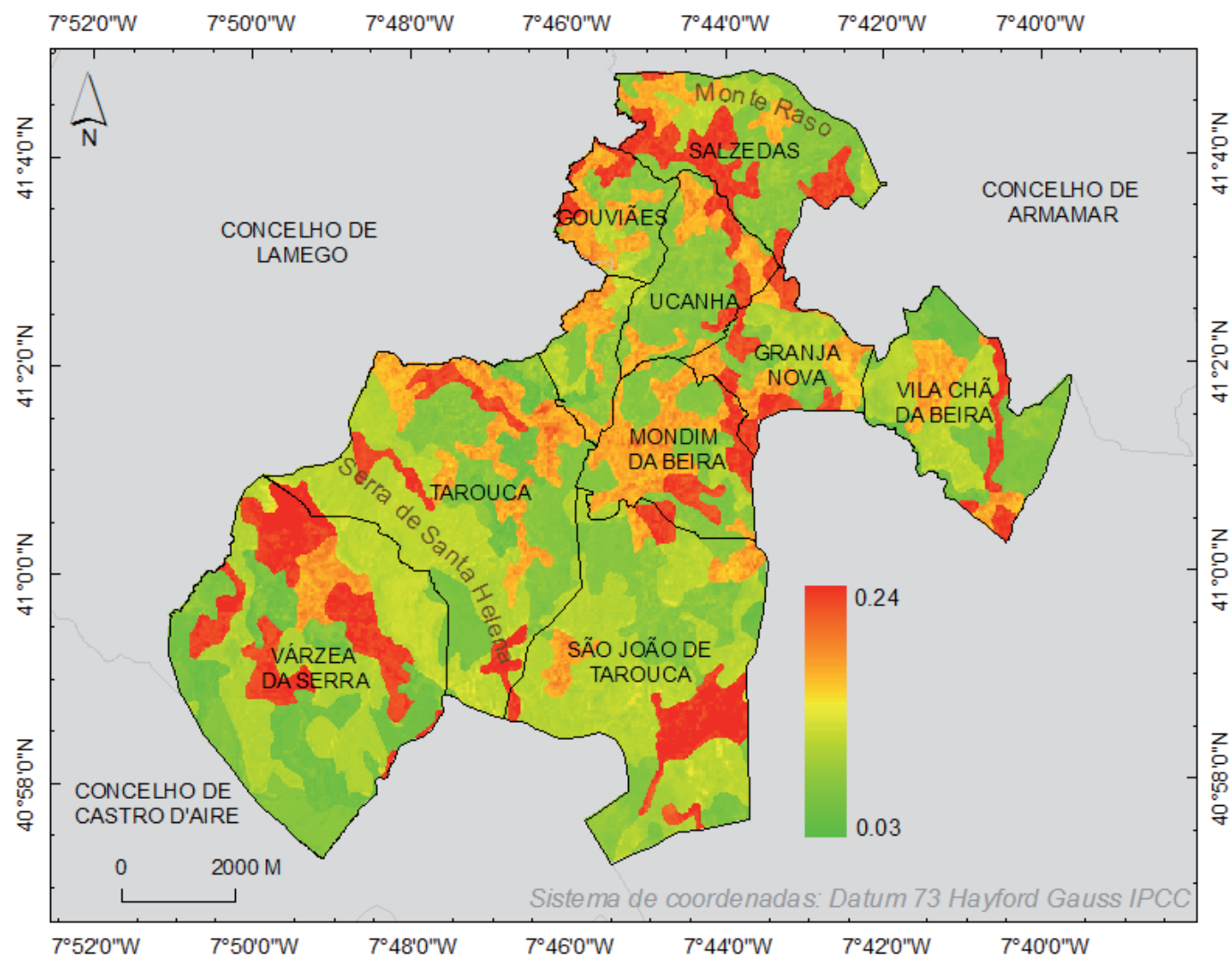

Figura 8 - Representação espacial do Fator Coberto do Solo (C). 


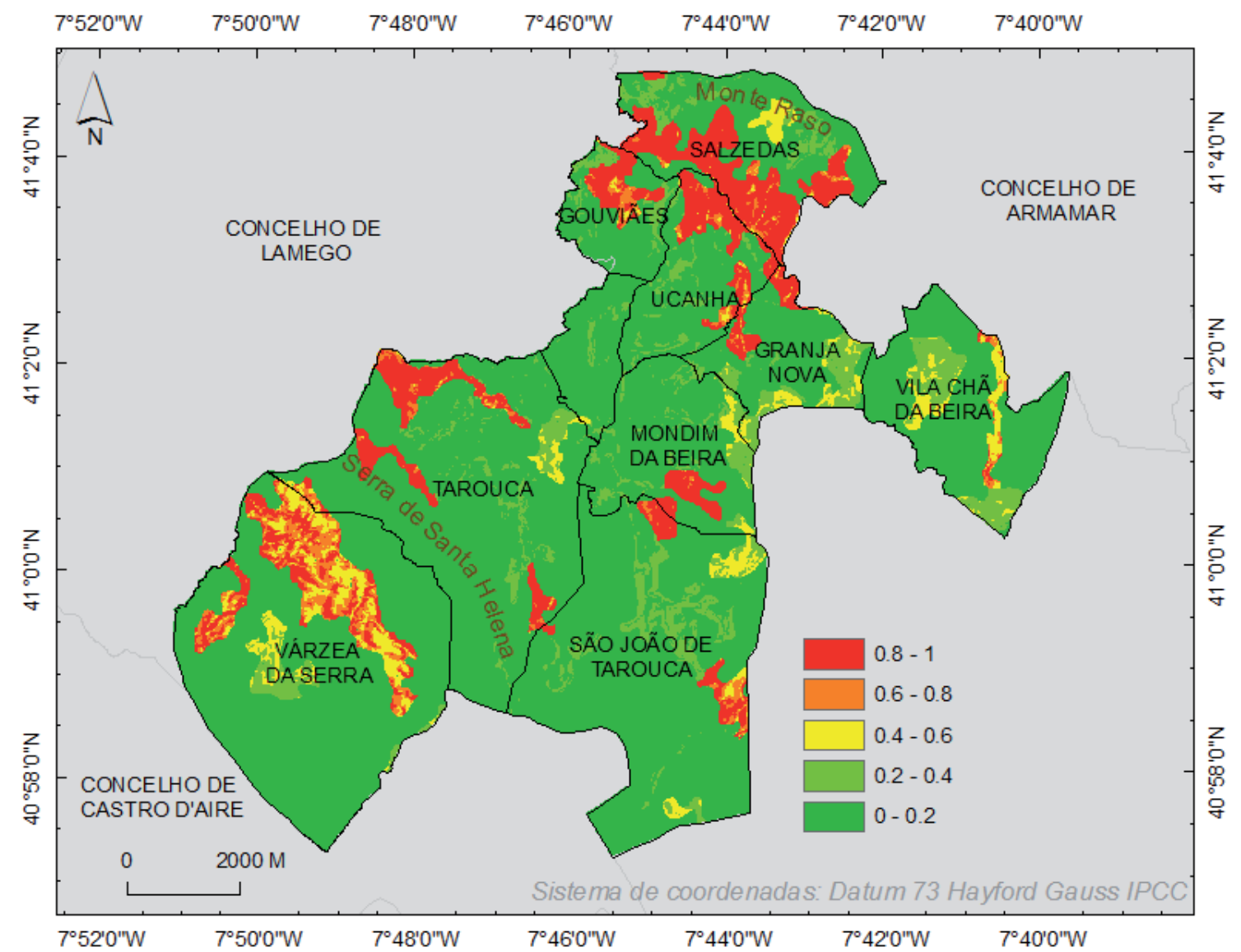

Figura 9 - Representação espacial do Fator Prática Agrícola (P).

Com o cálculo de todos os fatores que compõem a EUPS, calculou-se a probabilidade de perda de solo anual por erosão hídrica (erosão específica). Nos resultados obtidos (Figura 10) verificou-se que a maioria do território apresenta reduzida probabilidade de perda de solo por erosão hídrica, sobressaindo parte das vertentes da Serra de Santa Helena e do Monte Raso com os valores mais elevados, sendo estas as áreas que carecem de maior preocupação na tomada de decisões de conservação dos solos, visto serem maioritariamente usados para o desenvolvimento de atividades agrícolas (fonte de rendimento da população local) e outras atividades antrópicas.

Os resultados obtidos nesta avaliação vão de encontro às observações de campo, ou seja, os locais onde se observou maior perda de solo por erosão hídrica correspondem às áreas com a maior probabilidade de perda por este processo obtidas pela EUPS. Sendo estas perdas bastante elevadas nestas áreas (máximo de 311 ton.ha ${ }^{-1} \cdot$ ano $\left.^{-1}\right)$, este processo evidencia-se na modelação das vertentes da Serra de Santa Helena e também do Monte Raso.

Na Serra de Santa Helena há ainda outros problemas associados à erosão do solo, nomeadamente ocorrência de movimentos de vertente, e também o aumento de material deslocado nas escoadas (processos frequentes) devido à constante acumulação de sedimentos erodidos no fundo dos valeiros ou linhas de água. Ao aumentar o volume de material em movimento neste tipo de movimento de vertente, amplifica-se o seu potencial destrutivo a jusante, podendo trazer consequências danosas para a população aqui residente ao destruir os seus bens materiais, facto que já ocorreu na última década (Meneses, 2011b).

Estes movimentos de massa vão alterando as formas das vertentes, com destaque para a Serra de Santa Helena e Mote Raso, evidencia-se nestes movimentos o incremento das perdas de solo pela modificação ou remoção da sua proteção. 


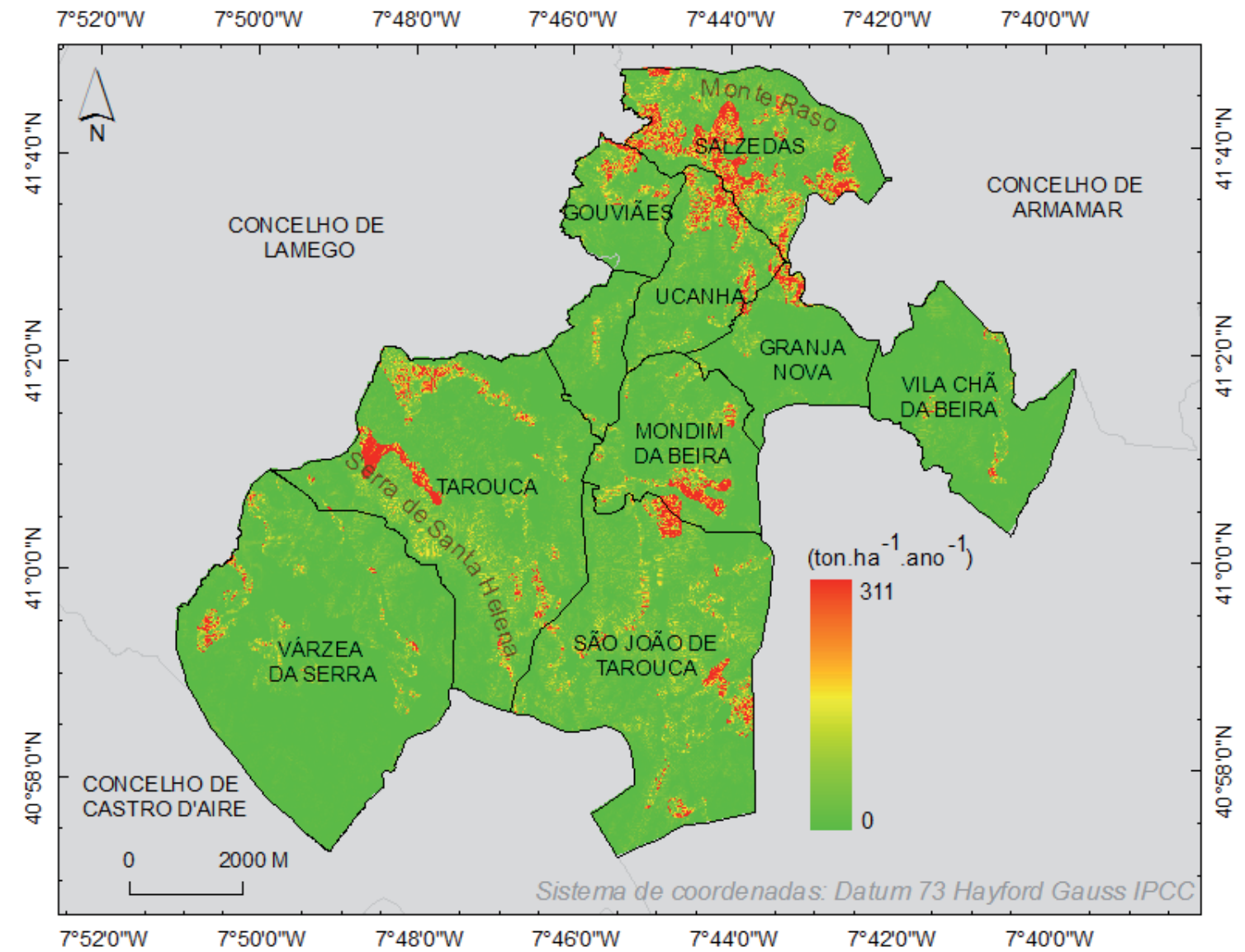

Figura 10 - Probabilidade anual de perda de solo por erosão hídrica.

\section{Conclusão}

As vertentes da Serra de Santa Helena destacam-se com a maior probabilidade de perda anual de solo por erosão hídrica, por um lado devido à extensão das vertentes e seu declive, por outro a inexistência de cobertura vegetal devido aos incêndios florestais. Nesta avaliação foi importante a integração de informação de ocupação do solo mais atualizada para a colmatação de eventuais erros resultantes do cálculo do fator $\mathrm{C}$ com informação desatualizada.

As perdas de solo nestas vertentes têm impactes na morfogénese atual da área de estudo, com destaque para a Serra de Santa Helena e também nas vertentes do Monte Raso localizado a norte da mesma. Contudo, no Monte Raso têm-se construído socalcos (regularização das vertentes), o que de certa forma irá contribuir para a atenuação da perda de solo por erosão hídrica.

As metodologias apresentadas neste estudo revelaram-se importantes, primeiro na determinação das áreas onde se deve atuar devido à maior probabilidade de perda de solo por erosão hídrica (permite a criação de medidas reativas), mas também na implementação de estratégias que visem a minimização de perdas de solo por este processo (medidas preventivas), o que poderá diminuir a probabilidade de ocorrência de outros tipos de movimentos de vertente e evitar consequências danosas.

\section{Referências Bibliográficas}

BEASLEY, D.; HUGGINS, L.; MONKE, E. ANSWERS: A model for watershed planning. Trans. of the American Society of Agricultural Engineers, v. 23, No 4, p. 938-944, 1980.

BERTONI, J.; LOMBARDI NETO, F. Conservação do Solo. Icone Editora, São Paulo, 1990.

BRILHA, J.; SÁ, A. O solo - pele da Terra. Prospecto relativo a um tema-chave do Ano Internacional do Planeta Terra 20072009, Planeta Terra Ciências da Terra para a sociedade, 2007.

DAVEAU, S. \& COLABORADORES. Mapas Climáticos de Portugal. Nevoeiro e Nebulosidade. Contrastes Térmicos. 
Centro de Estudos Geográficos, Memória N. ํ 7, Lisboa, 1985.

ENGEL, B. Estimating Soil Erosion RUSLE (Revised Universal Soil Loss Equation) Using Arcview. Purdue University, 1999.

FOSTER, G.; MEYER, L. Soil erosion and sedimentation by water - an overview. Procs. National Symposium on Soil Erosion and Sedimentation by Water, American Society of Agricultural Engineering, St. Joseph, Michigan, p. 1-13, 1977.

KNISEL, W. CREAMS: A field-scale models for chemicals, runoff and erosion from agricultural management systems. U.S. Department of Agriculture, Report 26, 1980.

LAL, R. Soil erosion impact on agronomic productivity and environment quality: Critical Review. Plant Science, v. 17, p. $319-464,1998$.

LANE, L.; NEARING, M.; LAFLEN, J.; FOSTER, G.; NICHOLS, M. Description of the US Department of Agriculture Water Erosion Prediction Project (WEPP) Model. In Parsons, A.; Abrahams, A. - Overland Flow: Hydraulics and Erosion Mechanics, UCL Press Ltd, London, UK, p. 377-391, 1992.

MENESES, B.M. Erosão Hídrica do Solo. Caso de Estudo do Concelho de Tarouca. Dissertação de Mestrado apresentada à Faculdade de Ciências Sociais e Humanas da Universidade Nova de Lisboa, Lisboa, 2011a.

MENESES, B.M. Susceptibilidade e Risco de Movimentos de vertente no Concelho de Tarouca. Dissertação de Mestrado apresentada ao Instituto de Geografia e Ordenamento do Território da Universidade de Lisboa, Lisboa, 2011 b.

MENESES, B.M. Análise das alterações do uso e ocupação do solo no Vale do Varosa (Portugal) mediante imagens Landsat-TM e sua influência na conservação do solo. GeoFocus, v. 13-1, p. 270-290, 2013a.

MENESES, B.M. A Ação dos Pipkrakes na Mobilização de Solo na Serra de Santa Helena. VI Congresso Nacional de Geomorfologia. Coimbra 2013, Actas/Proceedings, Coimbra, p. 213-217, 2013b.

MORGAN, R. The European Soil Erosion Model: an update on its structure and research base. In Rickson, R. - Conserving Soil Resources: European Perspectives, CAB International, Cambridge, UK, p. 286-299, 1994.

PEDROSA, A.; MARTINS, M. Precipitações extremas na
Região Demarcada do Douro: consequências geo-ambientais. Estudos \& Documentos, Douro 17, p. 207-232, 2004.

PETAN, S.; PINTO, F.; MIKO, M.; BARBOSA, J. Modelação da erosão do solo da hidrográfica do Rio Leça, com a equação RUSLE e SIG. Revista da Associação Portuguesa dos Recursos Hídricos, Vol. 31, N. ${ }^{\circ}$ 1, p. 99-110, 2010.

PIMENTA, T. Directrizes para a aplicação da Equação Universal de Perda dos Solos em SIG. Factor de Cultura C e Factor de erodibilidade do Solo K. INAG/DSRH, 1998.

RENARD, K. G., FOSTER, G. A., WEESIES, G. A., MCCOOL, D. K.;YODER, D. C. Predicting soil erosion by water: a guide to conservation planning with the revised universal soil loss equation (RUSLE). USDA Agricul. Handbook 703. Agricultural Research Service, Washington, DC, USA, 1997.

ROO, A.; WESSELING, C.; JETTEN, V.; RITSEMA, C. LISEM: a physically-based hydrological and soil erosion model incorporated in a GIS. HydroGIS 96: Application of Geographic Information Systems in Hydrology and Water Resources Management (Proceedings of the Vienna Conference, April 1996). IAHS Publ., N. ${ }^{\circ} 235,1996$.

SIMMS, A., WOODROFFE, C.; JONES, B. Application of RUSLE for erosion management in a coastal catchment, southern NSW. MODSIM 2003: International Congress on Modelling and Simulation, v. 2, Integrative Modelling of Biophysical, Social and Economic Systems for Resource Management Solutions, Australia, p. 678-683, 2003.

TOMÁS, P. Erosão hídrica do solo em pequenas bacias hidrográficas: Aplicação da equação universal de perda de solo. Lisboa, 1993.

WASSON, R. Detection and measurement of land degradation. Land Degradation - Problems and policies, Cap. 1.3., Physical and biological aspects of land degradation. University of Cambridge, Melbourne, Australia, p. 49 -70, 1987.

WISCHMEIER, W.; SMITH, D. Predicting rainfall erosion losses from cropland east of the Rocky Mountains: Guide for selection of practices for soil and water conservation. U.S. Department of Agriculture Handbook, N. ${ }^{\circ}$ 282, USDA, Washington, 1965.

WISCHMEIER, W.; SMITH, D. Predicting rainfall erosion losses: a Guide to conservation planning. Department of Agriculture Handbook, N. ${ }^{\circ}$ 537, USDA, Washington, 1978. 